\title{
RESENHA: \\ POR UMA DIDÁTICA DA MARAVILHA
}

\author{
REVIEW: \\ FOR A DIDACTIC WONDER \\ CRÍTICA: \\ PARA UNA MARAVILLA DIDÁCTICA
}

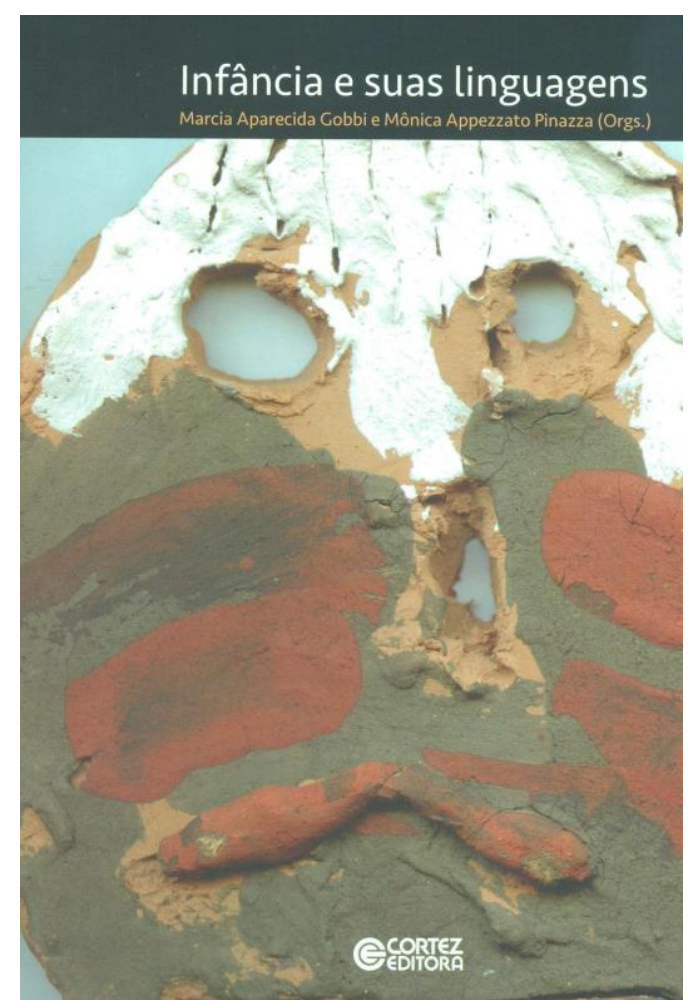

GOBBI, M. A.; PINAZZA, M. A. (Org.). Infância e suas Linguagens. São Paulo: Cortez, 2014. 
O livro Infância e suas linguagens, organizado por Marcia Aparecida Gobbi e Mônica Appezzato Pinazza, é resultado do Seminário Internacional, realizado no mês de maio de 2011 por essas duas pesquisadoras da infância, professoras da Faculdade de Educação da USP.

No prefácio do livro, a professora e pesquisadora do brincar infantil, Tizuko Kishimoto, apresenta "Infância e suas linguagens", ressaltando as contribuições das discussões trazidas pelos autores e autoras deste livro, comprometidos com a defesa de uma educação para as infâncias que valorize o imaginário, o lúdico e a expressão das crianças como sujeitos sociais e produtoras de cultura.

O livro é uma leitura obrigatória para aqueles/as que pesquisam e/ou atuam com a infância, porque propõe uma reflexão sobre os diversos campos de experiências presentes na educação da criança pequena. Artes, sonhos, literatura, imaginação, dança, desenho, ludicidade, emoções e fantasia são os temas que compõem os capítulos, embasados com sofisticadas teorias, numa abordagem poética e acessível para se pensar as práticas educativas.

No primeiro capítulo, as organizadoras do livro fazem um convite à leitura e defendem uma concepção de criança baseada em um ser ativo e sujeito de direitos, premissa para se pensarem e garantirem políticas públicas capazes de nortear a formação dos profissionais que atuam nas instituições de ensino infantil e o olhar dos pesquisadores interessados em pesquisar as infâncias por meio de suas expressões. Nesse sentido, cada capítulo da obra é apresentado, ressaltando as ideias centrais das temáticas abordadas pelos/as autores/as.

No segundo capítulo, Gobbi e Pinazza, ao tratar sobre "Infância e suas linguagens: formação de professores, imaginação e fantasia”, fundamentam-se nas teorias de Dewey, Vigotski e Bruner para explicar como a experiência, a estética e a cultura estão respectivamente, imersas nas brincadeiras e interações que as crianças vivenciam nas diversas formas de expressão. $O$ texto segue com diversas provocações sobre o envolvimento dos/as adultos/as com as crianças, propondo que, junto às crianças, a arteciência seja uma oportunidade para "estar" com as crianças, aprendendo com elas como se dá o processo criativo, quando espaços e tempos são planejados com liberdade para questionar, imaginar e criar. 
Juan Mata, pesquisador espanhol, no terceiro capítulo, traz "o direito das crianças de sonhar", por meio de um relacionamento íntimo e prazeroso com a linguagem. Ao longo do seu texto, provocador e reflexivo em relação à tomada de consciência, como leitores e professores/as de pequenos leitores, Juan Mata elucida múltiplas maneiras de explorar a linguagem com as crianças, de modo que elas criem gosto pelos livros, descobrindo nas leituras mundos possíveis de serem desvendados, imaginados e criados. O brincar com a poesia, o encantamento das peças teatrais e as surpresas presentes nos contos são apresentados às crianças como possibilidades de sonhar, imaginar, conhecer e compreender a vida de forma feliz, maravilhada, criativa e libertadora (MATA, 2014, p. $67)$.

O capítulo 4, escrito pela pesquisadora Isabel Marques, apresenta "os corpos e danças na educação infantil". Isabel Marques, pioneira nos estudos sobre dança no contexto da educação (no Brasil), direciona seu texto aos/às professores/as, chamando a atenção para aspectos da corporeidade das crianças e dos/as professores/as. Tais aspectos não podem passar despercebidos quando se pretende favorecer, também por meio das práticas educativas com danças, corpos que se portem de maneira "lúdica, criativa, autoral, relacional e crítica" (MARQUES, 2014, p. 73). Nesse sentido, Isabel Marques traz conceitos de cidadania também no ensino de dança na escola, ressaltando a importância sobre o conhecimento de como os corpos interagem dentro e fora da escola, por meio das experiências que vivenciam consigo mesmos, com o outro, com os espaços etc.. Conhecer como os corpos são percebidos e imaginados pelas crianças e pelos/as professores/as também se faz necessário, para que as propostas de dança na escola contemplem práticas educativas de autoria nas danças e construção de repertórios musicais que partam das necessidades e preferências dos seus protagonistas.

O professor italiano Gianfranco Staccioli, no capítulo 5, faz um percurso teórico para apresentar o campo de estudos do desenho infantil. Nesse percurso, o autor italiano vai apresentando, com os desenhos das crianças, as linhas de pesquisas, nas quais o desenho da criança é analisado, percorre as teorias: das fases psicológicas, artísticas e processuais, chamando a atenção para as possibilidades e os desafios que se encontram no interior de cada uma delas. Staccioli ressalta que diversos aspectos precisam ser levados em consideração quando se pretende "entrar no complexo mundo do desenho" (STACCIOLI, 2014, p. 111). Staccioli propõe uma linha de pesquisa que contribui com uma metodologia para o estudo do desenho infantil. Ele sugere cautela e disponibilidade 
para escuta diante dos "traços invisíveis" das crianças. Sua linha de pesquisa está interessada em compreender como as crianças transformam em imagens, suas percepções, seus pensamentos.

O capítulo 6, escrito pela artista e pesquisadora paulistana Edith Derdyk, é um convite para os professores e pesquisadores curiosos em investigar o desenho infantil, ao propor observar a dinâmica criativa que a criança elabora, por meio do corpo, da linha, do espaço e das cores que se desenham no papel ou nos suportes que a criança utiliza para desenhar. Derdyk aborda o desenho como fonte de pesquisa também para as crianças, principalmente quando têm a liberdade para criar desenhos sem a preocupação de corresponder às expectativas dos adultos, fazendo refletir sobre as concepções dos modos de aquisição de desenho na infância. Segundo a autora, o desenho parte de uma "ação expressiva para uma ação funcional" (DERDYK, 2014, p. 133), conjugando corpo e cultura na produção da criança.

No capítulo 7, a pesquisadora italiana Elisabetta Nigris discute novos paradigmas para a construção do conhecimento das crianças contemporâneas. Ela começa problematizando o modelo da didática tradicional, que é marcada pela transmissão do conteúdo de maneira mecânica e distante da realidade das crianças. Nigris propõe uma didática cuja abordagem parta das "curiosidades divertidas dos alunos" (NIGRIS, 2014, p. 149), permitindo às crianças que o ato educativo seja permeado de significado, imaginação, experiência, vivências estéticas... Nesse sentido, a autora italiana, em vez de propor regras, receitas e técnicas para explicar a didática da maravilha, traz aos profissionais que trabalham com a infância (0 a 10 anos) a reflexão sobre aspectos essenciais para essa nova didática, que não passa apressadamente pelas crianças e pelo conhecimento que se pretende construir, mas "acontece" no processo.

Ana Lúcia Goulart de Faria, no último capítulo, escreve sobre as "crianças pequenas e grandes, brasileiras e italianas", resultado do seu debate durante o seminário, com a italiana Elisabetta Nigris. Nesse texto, Faria expõe sua interlocução com Nigris em defesa do que a italiana chama de didática da maravilha, inspirada numa pedagogia não centrada no adulto e nos conteúdos, mas em uma abordagem que valoriza as expressões dos meninos e meninas, destacando a experiência, o lúdico, a imaginação, o corpo, as linguagens, nas produções das culturas infantis das crianças de $0-10$ anos de idade. Segundo Faria, se faz necessário problematizar o tipo de formação dos/as professores/as 
que trabalham com a infância no Brasil, pensando em novas organizações do espaço, tempo, materiais e, sobretudo, nas interações dos adultos com as crianças, possibilitando práticas de acesso "à arte e à cultura" (FARIA, 2014, p. 161), sem privar as crianças do prazer da descoberta e da convivência respeitosa na diversidade, por meio de uma pedagogia que ela tem denominado macunaímica, uma pedagogia antiadultocêntrica.

As discussões trazidas em cada capítulo do livro propõem uma prazerosa conversa sobre as crianças e suas expressões. Os autores e autoras defendem o direito das crianças de serem compreendidas como produtoras de cultura e nos presenteiam com olhares aguçados e maravilhados para práticas educativas que revelam os significados construídos por meninos e meninas sobre os mundos que os/as cercam.

Recebido em: 30/07/2015

Aprovado em: 12/04/2016 